\title{
Evaluation of the Compressive Strength of Hybrid Clay Bricks
}

\author{
O. Azeez ${ }^{1}$, O. Ogundare ${ }^{1 *}$, T.E. Oshodin ${ }^{1}$, O.A. Olasupo ${ }^{2}$, and B.A. Olunlade ${ }^{1}$ \\ ${ }^{1}$ Engineering Materials Development Institute P.M.B. 611 Akure Nigeria. \\ ${ }^{2}$ National Agency for Science and Engineering Infrastructure P.M.B. 391 Garki Abuja \\ Nigeria.
}

*Corresponding Author: suppiedee@yahoo.com

\begin{abstract}
This work has presented the evaluation of the compressive strength of hybrid clay bricks from interlocking brick making machine. The mixture of clay and cement at varying proportions was loaded into the mould compartment, mechanically rammed and hydraulically controlled.

The raw clay was sourced from Ilesa and Akure in the south-western part of Nigeria. The results showed that when the cement content was 6\%, the highest compressive load and energy at break were obtained in hybrid bricks from both Ilesa and Akure samples. However, the optimum service performance under compressive loading was attained at $6 \%$ cement in Ilesa hybrid bricks. Ilesa hybrid bricks possess better reliability and workability under loading than the Akure bricks.
\end{abstract}

Keywords: Hybrid bricks, compressive strength, clay, cement, interlocking machine.

\section{INTRODUCTION}

Clay based material is one of the materials that has been widely used in construction materials instead of wood, sand, concrete and other waste materials. This material is a major compound in clay brick, clay tiles and clay roofing tiles due to its wide-ranging properties, high resistance to atmospheric condition, geochemical purity, and easy access to its deposits near the earth's surface and low price. Fired clay brick (FCB) can be categorized as one of the demolition wastes as most of the unwanted FCB from buildings or houses renovation are being illegally disposed off in most places. The utilization of this type of clay based waste materials would replace the natural aggregates in concrete mixture [1]. Studies related to ancient clay bricks alone deal mainly with physical, chemical, and mineralogical composition $[2,3,4]$, durability and deterioration agents [5] and deterioration modelling $[6,7,8]$ neglecting the mechanical properties. 
The compressive strength is a mechanical property used in brick specifications, which has assumed great importance for two reasons. Firstly, with a higher compressive strength, other properties like flexure, resistance to abrasion, etc., also improve. Secondly, while other properties are relatively difficult to evaluate, the compressive strength is easy to determine [9]. Generally, compressive strength decreases with increasing porosity but strength is also influenced by clay composition and firing.

Compression testing is a method for assessing the ability of a material to withstand compressive loads. This test is commonly used as a simple measure of workability of material in service. Materials behave differently in compression than they do in tension so it may be important to perform mechanical tests which simulate the condition the material will experience in actual use. Compression testing is typically carried out on the following materials; Plastics, Foams, Rock, Concrete and Asphalt. It is rarely used to test metals [10]. Compressive strength of Blocks and Bricks is a critical parameter for determining the quality of these materials. The loads and forces acting on these materials while in service are compressive in nature and their ability to withstand such loads and forces without failure is a measure of their reliability [11].

The tasks of inspection and diagnosis of ancient buildings require obtaining a certain number of parameters, which provide information about the properties of the materials, the structural behaviour, or possible defects. Mechanical characterization is a fundamental task for the structural works and safety assessment, where the compression strength is a key parameter in the case of masonry structures. In fact, the compressive strength of masonry in the direction normal to the bed joints has been traditionally regarded as the sole relevant structural material property, at least until the recent introduction of advanced numerical methods for masonry structures [12].

The aim of this research is to evaluate the compressive strength of hybrid bricks from 8mould interlocking brick making machine.

\section{MATERIALS AND METHODS}

\subsection{Materials}

The samples were collected from certain locations in Ilesa and Akure in South western part of Nigeria. The Ordinary Portland Cement (OPC) was obtained commercially.

\subsection{Method}

The clay sample was mixed with water to desired consistency. Ordinary Portland Cement (OPC) was added in different percentages ranging from $0 \%-14 \%$ putting into consideration the volume of each mould. The OPC was thoroughly mixed with the clay sample for even distribution and homogeneity. The aggregate was loaded into the eight moulds of the interlocking machine. After sometime, the hydrid bricks were hydraulically lifted out of the 
moulds. The interlocking machine used for this research was the 8- Mould Interlocking Earth Brick Making Machine which was designed, developed and fabricated at Engineering Materials Development Institute Akure Nigeria. Each sample was left for the first 28 days for proper curing and sufficient strength before compression testing was carried out.

\subsection{Compression Testing Procedure}

For the compression test, the specimens were cut from the bricks to be tested in the direction of the moulding or perpendicular to bed joints (see Fig.1), which is the usual loading direction in building elements (e.g., walls and vaults) subjected to dead load. Generally, very small specimens were obtained, with typical cross sections of $30 \mathrm{~mm}$ x $30 \mathrm{~mm}$ and $30 \mathrm{~mm}$ of height. All specimens were ground using a rectifying machine, so that the loading faces were properly aligned. The test setup for the compression tests was carried out on Instron Universal Tester model 3369 available at the Engineering Materials Development Institute Akure Nigeria. Its steel frame was equipped with a compression load cell with a maximum capacity of $50 \mathrm{kN}$ and connected to a software- driven computer system. The steel platens were rectified in order to provide a flat surface. The lower platen has a spherical seat made of tempered steel that allows the initial alignment and accommodation of the specimen, thus facilitating the alignment of the applied load with the centre of the specimen as well as preventing any other unfavourable effect due to geometrical imperfection of the specimen. The Instron software was programmed to capture all data during the course of the test.

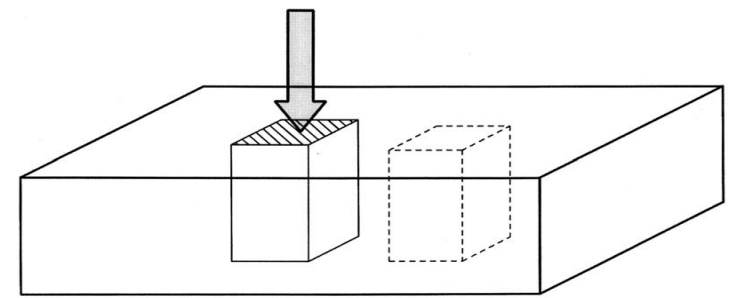

Fig. 1 Schematics showing how specimens were cut from bricks and direction of compression tests

\section{RESULTS AND DISCUSSION}

Figure 2 shows the bar chart of compressive load at break of hybrid bricks made from Ilesa samples. The mixing of Ordinary Portland Cement (OPC) in different percentages has revealed the different compressive strengths. It was observed that when no cement $(0 \%$ cement content) was mixed, a compressive strength of $727.91 \mathrm{~N}$ was obtained. This shows the fact that the virgin clay sample possesses a reasonable compressive strength. With $4 \%$ cement mixed with the clay sample, a compressive load at break (crushing strength) of $481.03 \mathrm{~N}$ was obtained. It was observed that when $6 \%$ cement was mixed with the clay sample before loading into the interlocking machine, the highest compressive load at break of $2,537 \mathrm{~N}$ was obtained. This shows that $6 \%$ hybrid bricks will be able to withstand $2537 \mathrm{~N}$ before failure under loading. This is because at this percentage, the cement elements were 
able to penetrate most into the matrix of the clay resulting in strong interlinking and bonding network of the hybrid brick. This means that in service, $6 \%$ hybrid bricks will be used under compressive loading up to $2,537 \mathrm{~N}$.

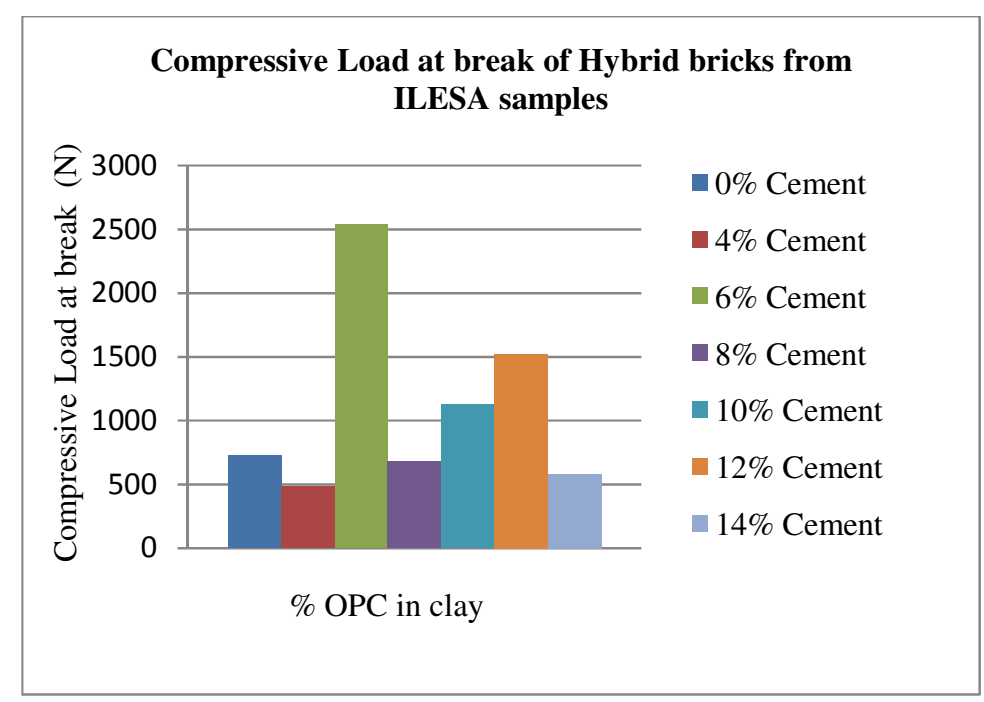

Fig. 2 Compressive Load at break of hybrid bricks from Ilesa samples

Figure 3 shows compressive load at break of hybrid bricks from Akure samples. It was observed that the highest compressive load was obtained at $8 \%$ cement ratio and followed by $14 \%$ cement ratio. This was closely followed by $6 \%$ cement ratio. This is because the cement elements were able to intertwine the network of the clay elements at the highest capacity at $8 \%$ cement ratio. This resulted in formation of strong matrix of the hybrid bricks with the same compressive stress values of $1.12 \mathrm{MPa}$ and $1.11 \mathrm{MPa}$ at $6 \%$ and $14 \%$ cement ratio respectively as shown in figure 4 below.

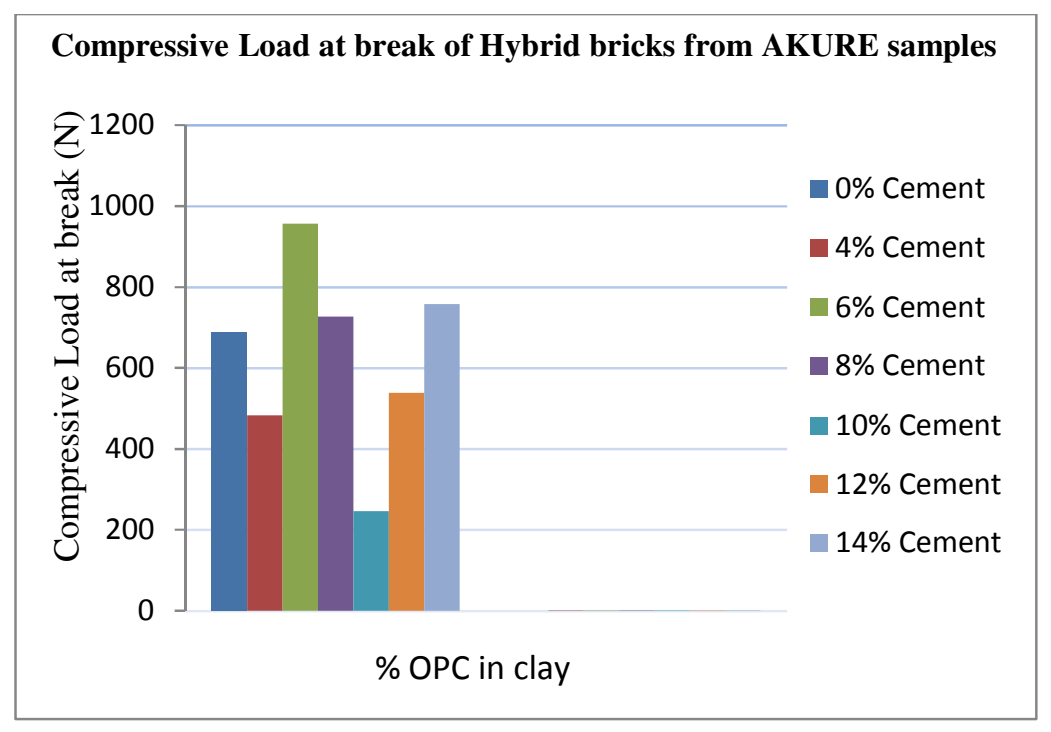

Fig. 3 Compressive Load at break of hybrid bricks from Akure samples 


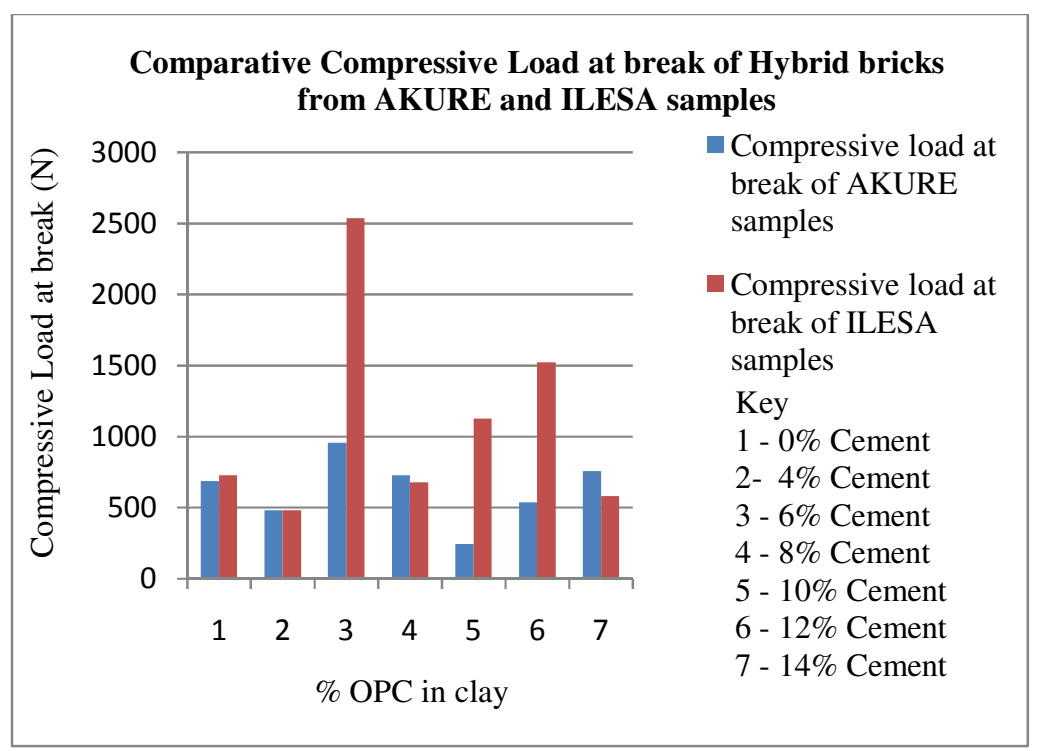

Fig.4 Comparative Compressive Loads at break of hybrid bricks from Ilesa and Akure samples

The comparative compressive loads at break of hybrid bricks from both Ilesa and Akure samples are presented in figure 4 above. At a glance, it can be observed that at $0 \%, 6 \%, 10 \%$ and $12 \%$ cement ratios, the compressive resistance of Ilesa Hybrid bricks are better than that of Akure. This may be due to geographical and environmental factors on the virgin clay since that same ordinary Portland cement was mixed

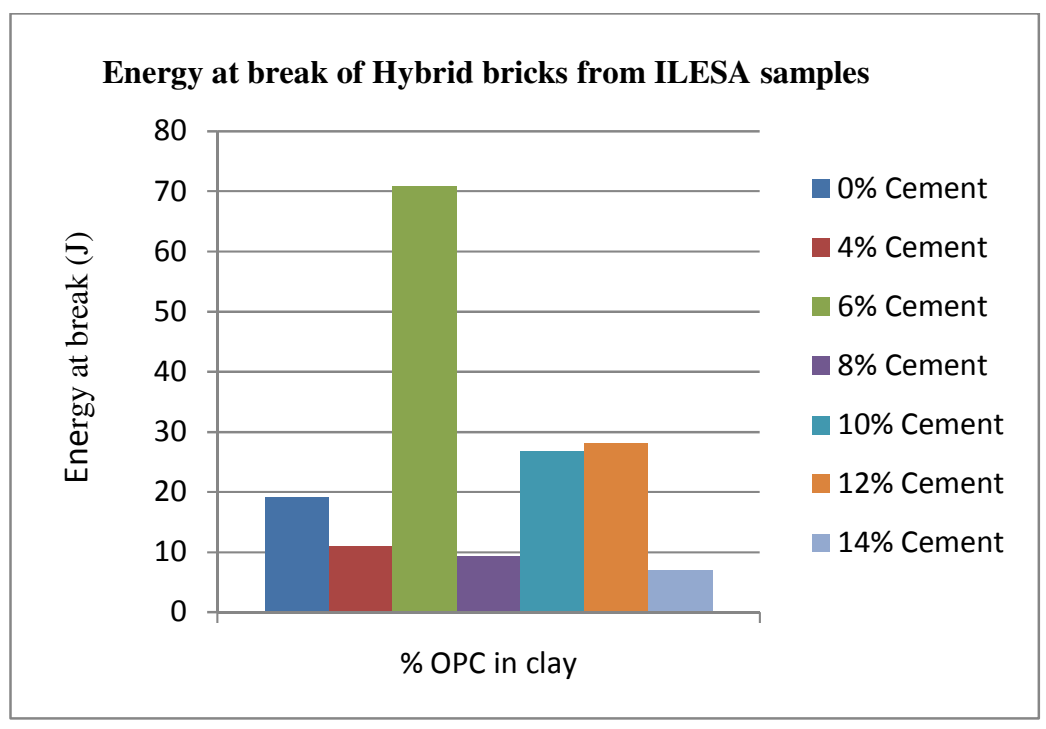

Fig.5 Energy at break of hybrid bricks from Ilesa samples 


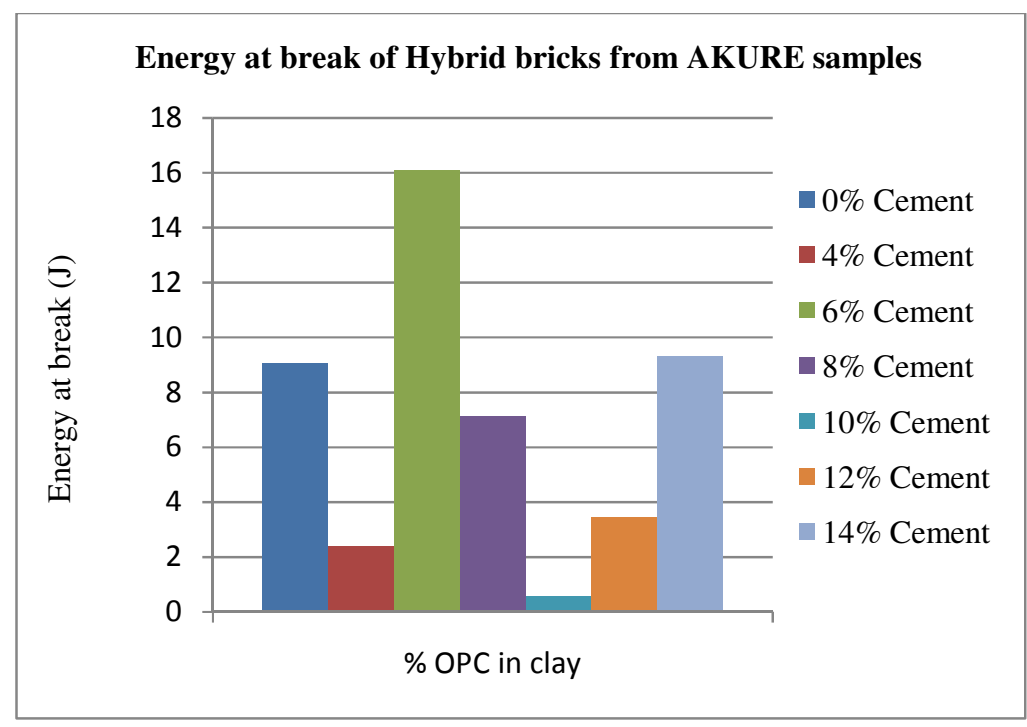

Fig. 6 Energy at break of hybrid bricks from Akure samples

Figure 5 is a bar chart of energy at break of hybrid bricks from Ilesa samples. It shows that energy absorbed $(71 \mathrm{~J})$ before failure is greatest at $6 \%$ cement ratio. This is to support the highest compressive load at break that also occurred at 6\% cement ratio (see Fig. 2 above). In other words, the energy absorbed is directly proportional to the compressive strength characteristics. This is due to high adhesive property between the clay and the cement particles resulting in high resistance to dislocation stress.

Figure 6 is a bar chart of energy at break of hybrid bricks from Akure samples. It can be observed that the highest energy absorbed before break of $16 \mathrm{~J}$ was at $6 \%$ cement ratio.

\section{CONCLUSION}

On the strength of the results presented above, it can be concluded that

1. The optimum service performance under compressive loading was attained at $6 \%$ cement in Ilesa hybrid bricks.

2. Ilesa hybrid bricks possess better reliability and workability under loading than the Akure bricks.

3. Ilesa clay has better binding characteristics and quality than the Akure species.

\section{REFERENCES}

[1] Ummi Kalsum, H.M.N, Mashitah, M.D. and Badorul, A.B. 2008. Recycling of clay based demolition wastes for the production of concrete block. A paper delivered at International Conference on Environment (ICENV 2008).

[2] López-Arce, P., Garcia-Guinea, J., Gracia, M., and Obis, J. 2003. "Bricks in historical buildings of Toledo City: Characterization and restoration.” Mater. Charact., 50, 59-68. 
[3] Cardiano, P., Ioppolo, S., Stefano, C., Pettignano, A., Sergi, S., and Piraino,P. 2004. "Study and characterization of the ancient bricks of Monastery of "San Filippo di Fragalà” in Frazzanó_Sicily_.” Anal. Chim. Acta, 519 (1), 103-111.

[4] Pauri, M., Stazi, A., Mastrosanti, F., and D’Orazio, M. (1994). “The decay of ancient building masonry, a case study." Proc., 10th International Brick/Block Masonry Conference Calgary, Canada, 1295-1304.

[5] Wijffels, T., and Nijland, T. G. 2004. "Deterioration of historic brick masonry due to combined gypsum, ettringite and thaumasite: A case study." Proceedings of 13th International Brick/Block Masonry Conference, Amsterdam, The Netherlands, 809-815.

[6] Cultrone, G., De la Torre, M. J., Sebastian, E. M., Cazalla, O., and Rodriguez-Navarro, C. 2000. "Behavior of brick samples in aggressive environments." Water, Air, Soil Pollution, 119, 191-207.

[7] Binda, L., Baronio, G., and Ferrieri, E. D. _1996a_. "Full-scale models for the calibration of laboratory ageing tests." Proceedings of 7th International Conference on Durability of Building Materials and Components, Stockholm, Sweden, 559-568.

[8] Binda, L., Baronio, G., and Ferrieri, E. D. 1997. "Durability of brick masonry surface treatments to salt crystallization." Proc., 11th International Brick/Block Masonry Conf., Shanghai, China, 732-747.

[9] Adeola, J.O., 1977. A Review of Masonry Block/Brick Types Used for Building in Nigeria. Unpublished M.Eng. Thesis, University of Benin, Benin-City.

[10] Bukar, Y. A. 1992. "Benefits of Enhanced Product Quality for Industries like Aluminum, Steel, Auto Mobile and related Industries" been paper presented the seminar on Strategy for developing Local Raw Materials for Metallurgical and Building Industries.

[11] Hassan, A.B. and Bukar, Y. A. 2009. Design and Fabrication of a Compression Strength Testing Machine for Blocks and Clay Bricks. Leonardo Electronic Journal of Practices and Technologies. 14,142-153.

[12] Francisco Fernandes and Paulo B. Lourenço. 2007. Evaluation of the Compressive Strength of Ancient Clay Bricks Using Microdrilling. Journal of Materials in Civil Engineering, 19(9): 791-800. 